\title{
NOVOS CAMINHOS DO TRÁFICO ATLÂNTICO: CATIVOS AFRO-PORTUGUESES NO BRASIL COLONIAL
}

VENÂNCIO, Renato Pinto. Cativos do Reino: a circulação de escravos entre Portugal e Brasil, séculos 18 e 19. São Paulo: Alameda, 2012. 276 p.

$E_{\text {la se chamava Ângela da Cruz e }}$ declarou ser "preta cativa", nascida em 1716, na vila portuguesa de Estremoz, no Alentejo. Na tenra infância, aos nove anos de idade, foi comprada por traficantes lisboetas e levada para o Rio de Janeiro, mas logo foi vendida para Antônio Teixeira, que a levou para a freguesia de São Caetano, pertencente à Vila do Carmo, atual Mariana, Minas Gerais. Depois de três anos, novamente mudou de senhor, agora João Francisco Guimarães, que a violou, mas depois lhe concedeu a alforria. Sua liberdade foi comprada pelo português Domingos Fernandes Carvalho, que se tornou depois seu marido. Na época, ele tinha 45 anos, era de Barcelos, enriqueceu na capitania como senhor de engenho e se tornou um dos homens mais abastados do lugar. Viveram durante alguns anos juntos, em concubinato, mas diante da ameaça de uma devassa eclesiástica na região, resolveram se casar, e foi aberto um processo matrimonial em 1737, documento que descortinou para nós parte da vida desta escrava e depois forra portuguesa.

A trajetória de Ângela da Cruz, contada por Renato Pinto Venâncio em Cativos do Reino, apresenta-nos um aspecto interessantíssimo, mas ainda pouco estudado pela vasta historiografia sobre a escravidão: a circulação de cativos entre Brasil e Portugal e a presença dos afro-portugueses no Brasil. A riqueza e a complexa dimensão destes contatos reconta, por outros ângulos, a história da escravidão no mundo luso-brasileiro. Contrariamente à tendência de fixação da população escrava após o tráfico atlântico, a pesquisa de Renato Pinto Venâncio constatou percursos por vezes raros e surpreendentes de circuitos inimagináveis de circulação de escravos e forros. 
É relativamente recente no Brasilo interesse pela presença dos africanos e afrodescendentes em Portugal. Na própria historiografia lusa, o tema não é dos mais frequentes. Nos clássicos da história portuguesa e na obra dos folcloristas, as culturas negras aparecem, quando muito, através de vestígios e traços fragmentários, em regra, atreladas ao movimento de expansão lusitana em direção à África, restringindose, assim, aos séculos XV e XVI. Os estudos mais específicos tiveram em Antônio Brasio e José Ramos Tinhorão expoentes importantes, ${ }^{1}$ e mais recentemente, Didier Lahon, Jorge Fonseca, A.C. Sauders, Alberto Vieira, Manuel Valença e Maria do Rosário Pimentel contribuíram sobremaneira para a discussão da escravidão e da presença desta população negra em Portugal. $^{2}$

\footnotetext{
1 Antônio Brasio, Os pretos em Portugal, Lisboa: Agência Geral das Colônias, 1944; José Ramos Tinhorão, Os negros em Portugal: uma presença silenciosa, Lisboa: Caminho, 1988.

2 Manuel Valença, A escravatura na região do Porto (1591-1795), Braga: Franciscana, 2003; Alberto Vieira, Os escravos no arquipélago da Madeira, séculos XV-XVII, Funchal: Centro de Estudos da História do Atlântico, 1991; A. C. de C. M Saunders, História social dos escravos e libertos negros em Portugal (1441-1555), Lisboa: Imprensa Nacional, 1994; Jorge Fonseca, Os escravos em Évora no século XVI, Évora: Câmara Municipal de Évora, 1997; Maria do Rosário Pimentel, Viagem ao fundo das consciências: a escravatura na Época Moderna, Lisboa: Colibri, 1995; Didier Lahon, O negro no coração do Império: uma memória a resgatar. Séculos $X V$-XI, Lisboa:
} Ministério da Educação, 1999.
Embora a escravidão não tenha sido determinante na economia portuguesa, não se constituindo como um sistema escravista comparável ao Brasil, os africanos marcaram presença naquela sociedade. E alguns dos circuitos de migração destes cativos Renato Pinto Venâncio apresentounos ao longo dos oito capítulos de seu livro. O cenário principal foi a região das Minas Gerais no século XVIII, que, pela presença do ouro a partir de finais do século XVII, foi grande pólo de atração de poderosos movimentos migratórios. Assim, no capítulo 1, "A circulação de cativos", é mostrado ao leitor um painel geral destes circuitos não convencionais do tráfico. A pesquisa foi difícil, pois a emissão de documentos de identificação, nos quais era indicado o nome do imigrante, sua família, agregados e escravos, era rara no Brasil na época. O controle da entrada de "estrangeiros" era difícil, como bem demonstrou o autor ao discorrer sobre o tema com grande domínio da documentação e da bibliografia auxiliar. Os registros paroquiais de batismo, casamento e óbito tampouco eram consistentes pela falta de séries completas. Assim, a base documental utilizada foram as séries relativas aos Reais Quintos (1710-1725), taxa de dez oitavas de ouro em pó sobre cada escravo de mineradores e faiscadores, e ainda a Capitação (1735-150), que estendeu esta cobrança aos negros, 
mulatos e mestiços livres que não tivessem escravos próprios, artesãos, donos de lojas e de hospedarias. ${ }^{3}$ Foi a partir destas listas, em que constavam os nomes dos proprietários e dos respectivos escravos, com as suas diversas origens, que Venâncio detectou os cativos do Reino. Eram exceção nas senzalas, pelo menos no período entre 1718 e 1738 , chegando a um percentual de $0,3 \%$. Este material também permitiu o levantamento nominal dos senhores e a quantidade de escravos lusos que cada um possuía. A pesquisa permite ao leitor conhecer algumas histórias interessantes de alguns desses personagens, desvendadas pelo autor com maestria e ótima narrativa. Venâncio conclui que, de acordo com sua amostragem, possuir um escravo oriundo de Portugal era privilégio de poucos senhores abastados ou funcionários de alto escalão da administração colonial.

Como entender os mecanismos e a dinâmica de circulação desses cativos? Venâncio apresenta-nos um dado que passou ao largo da imensa maioria dos escravos afro-brasileiros: a qualificação profissional. João Batista de Oliveira, por exemplo, rico proprietário de nada menos que 79 escravos em Diamantina, comprara o escravo Maurício, 37 anos, que era ferra-

3 Charles Boxer, A Idade de ouro no Brasil: dores de crescimento de uma sociedade colonial, São Paulo: Companhia Editora Nacional, 1969, p. 217. dor em Lisboa. Em 1767, foram importados vários escravos ferreiros da Bahia para prover uma oficina em Angola, e também, na mesma época, escravos indianos para ensinar o cultivo da canela, palmeira e pimenta, a cultura do linho e a fabricação de vidros no Brasil.

A pena do degredo também fez circular cativos pelo Império Português. O tribunal inquisitorial lusitano, criado em 1536 , foi pródigo neste sentido, condenando escravos e forros por diversas condutas heréticas e penalizando-os, dentre outras sentenças, com a expulsão de seus lugares de origem. Venâncio contanos o caso de Estevão Luis, nascido em Évora, acusado de pacto demoníaco e sodomia, cuja sentença, proclamada em 1690, foi de seis anos de degredo para o Brasil. O caminho inverso também foi percorrido por todos aqueles que, no Brasil, foram enviados a Lisboa como réus, uma vez que a Inquisição não estabeleceu aqui nenhum tribunal. Feiticeiros, sodomitas, blasfemos, condenados pelo Santo Ofício português, integraram este circuito de escravos e forros hereges, que uma vez degredados acabavam por continuar a difundir suas crenças nos locais onde haviam sido condenados a refazerem suas vidas. Destacaríamos, especificamente, o caso das práticas mágico-religiosas, que acabaram por se alastrar para outras paragens do Império. Que 
o diga o exemplo de Domingos Álvares, natural da Costa da Mina, preso em 1744 no Rio de Janeiro por suspeitas de curandeirismo envolvendo pacto demoníaco. Degredado para Castro Marim, lá continuou praticando suas curas, e de novo foi pego pela Inquisição. A sentença: novo degredo, desta vez para Bragança. O uso de patuás e amuletos protetores - as chamadas bolsas de mandinga -, sobretudo no século XVIII, é outro exemplo dessa circularidade. O comércio das bolsas de mandinga que se estabeleceu entre escravos e forros oriundos do Brasil e Portugal está registrado nos arquivos inquisitoriais, posto que foram consideradas práticas de feitiçaria. ${ }^{4}$

Nestes processos movidos pelo Santo Ofício, evidencia-se claramente a dinâmica da mobilidade geográfica dos escravos em função do trânsito de funcionários do Reino, da burocracia colonial e dos comerciantes, que ficavam no ir-e-vir entre Brasil e Portugal com seus cativos, permanecendo determinados períodos ora num, ora noutro lugar. ${ }^{5}$ E muitas ve-

4 Daniela Calainho, Metrópole das mandingas: religiosidade negra e Inquisição portuguesa no Antigo Regime, Rio de Janeiro: Garamond, 2008; e James Sweet, Domingos Álvares, African Healing, and the Intellectual History of the Atlantic World, Chapel Hill: North Carolina University Press, 2011.

A. J. R. Russell-Wood, "Governantes e agentes", in Francisco Bethencourt e Kirti Chaudhuri (orgs.), História da expansão portuguesa (Lisboa: Círculo de Leitores, 1998), v. 3, pp.169-92. zes, também, compravam e vendiam escravos, incrementado mais ainda esta circulação.

No capítulo 2, "Trajetórias coloniais", chega a vez dos estudos de caso, em que a escolhida foi Ângela da Cruz, com quem começamos esta resenha. Sua trajetória permitiu ao autor analisar uma série questões importantes no mundo colonial: o concubinato, o matrimônio, a legislação eclesiástica colonial, os esforços moralizantes da Igreja e seus mecanismos persecutórios, a exemplo da devassa de 173334. A vida dessa forra portuguesa mostrou a possibilidade de integração à sociedade senhorial através da compra da liberdade e do casamento, superando os percalços de sua venda ainda menina, da violação sofrida por um dos senhores, e da acusação de concubinato e "tratos ilícitos" com outro português. Ela própria, depois do matrimônio, como está disposto em seu inventário de morte, de 1744, tornouse senhora de escravos e usufruiu de tudo que uma mulher branca de elite poderia: sobrenome, vestuário fino, imagens sacras por sobre a roupa. Renato Pinto Venâncio mostrou com grande domínio da documentação, que para além da mobilidade, Ângela da Cruz foi exemplo de um raro processo de ascensão social vivenciado por uma ex-escrava.

Exceções à parte, a regra para os cativos do Reino era um visão negativa e pejorativa sobre sua existência, 
que o autor percebeu com clareza na documentação. Mal cheirosos e repugnantes, dentre outros atributos, era como eles apareciam na literatura de cordel do século XVIII de grande circulação em Portugal. Para Venâncio, é sinal indicativo da presença de escravos em Lisboa, tema do capítulo 3, "Escravos de Lisboa". A partir do balanço estatístico sobre o tráfico atlântico, ancorado na bibliografia clássica sobre o tema, o autor especifica os dados para Portugal, sublinhando o caráter residual da escravidão portuguesa, chegando no século XVII, por exemplo, a parcos 3,3\% nas províncias tradicionalmente escravistas da Estremadura, Alentejo e Algarve. O impacto que esta população causou nos viajantes foi valorizada pelo autor, bem como a investigação nas Ordenações do Reino, tendo ele nesta encontrado várias medidas relativas ao controle e circulação dos cativos em Lisboa. Outra fonte importante foram as atas eclesiásticas de casamentos, pesquisa ampla, pela existência de 36 paróquias na cidade no século XVIII, mas que permitiu, por amostragem, registrar que $4,6 \%$ do conjunto dos casamentos realizados entre 1700 e 1725 eram de escravos.

A Lisboa setecentista também recebeu uma população escrava vinda da América. Dito pelo próprio Venâncio, "tratava-se do mundo de ponta-cabeça, de uma brutal inversão: a Colônia povoando a metrópole com as "classes perigosas"” (p. 89). O ano de 1755 mostrou que dos 354 passageiros que saíram do porto do Rio de Janeiro para Lisboa, 41\% eram escravos.

Aspecto também notável da circulação de cativos foi o tráfico de pigmeus, objeto do capítulo 4 . Acompanhando a tradição europeia da presença de bufões e bobos da corte, apresentada pelo autor, a população negra se fez presente nesta atividade na corte portuguesa. No século XVIII, já estavam também nas casas mais abastadas, como serviçais domésticos, muitos dos quais anões, para diversão dos senhores e seus convidados. O crescente interesse pela História Natural na época levou à aquisição de africanos especiais, de baixa estatura - os pigmeus -, junto a espécies de plantas e animais, como mostrou, por exemplo, a correspondência trocada entre os governadores de Moçambique e Bahia, em 1786, quando o primeiro solicitou ao segundo que remetesse um casal de anões africanos, prontamente embarcados junto com mudas de plantas da região.

Os últimos capítulos do livro tratam, fundamentalmente, do declínio e da extinção progressiva da escravidão em Portugal. No capítulo 5, "Os cativos contra o Reino”, Venâncio recupera os percalços da legislação, iniciada com um alvará de 1761 proibindo a entrada de escravos, mas 
enfatiza o papel das ações de liberdade impetradas junto à justiça portuguesa pelas irmandades religiosas ou pelos próprios cativos, incluindo aqueles oriundos do Brasil que houvessem permanecido no Reino por determinado tempo. E mais interessante ainda foram os mecanismos apontados pelo autor para a difusão destas perspectivas de liberdade, como foi o caso dos escravos que atuavam nas embarcações marítimas. As estatísticas eram inequívocas: entre 1755 e 1800 , de quinze navios lusobrasileiros, apenas $12,2 \%$ da tripulação era composta por brancos. A "cultura da liberdade" nos meios marítimos era também extremamente atrativa para os fujões, que passando-se por homens livres tentavam embarcar (p. 149). A circulação dessas informações, afirma o autor, foi se fazendo, sobretudo, pela cultura oral, uma vez que o acesso à alfabetização da população escrava era quase nenhum, tema discutido no capítulo 6, “Os escravos sabiam ler?".

Preocupado com a difusão cultural propiciada pela circulação de cativos, em "Todos somos filhos de Adão e Eva”, capítulo 7, Venâncio dedica-se aos provérbios e máximas circulantes no mundo luso-brasileiro setecentista e oitocentista, por vezes apropriadas pelos escravos e forros. Mas eles próprios apareceram pouco nesses ditados populares, valendo mencionar aqui, no entanto, o registro de dois deles em especial: "Ainda que somos negros, gente somos, e alma temos"; e "Todos somos filhos de Adão e Eva, só a vida nos diferença [sic]”' (p. 205).

Finalmente, no derradeiro capítulo, "Os últimos senhores do reino", já no século XIX, com a escravidão em Portugal extinta - embora não tenha havido nenhuma lei específica decretando a abolição -, o foco são os senhores que, tendo retornado a Portugal, possuíam cativos no Brasil. Por outro lado, em meio ao grande movimento migratório para o Brasil após a independência, Venâncio sugere que os afro-portugueses tiveram o mesmo destino, dado o sumiço de referências a eles a partir de meados do século XIX.

Cativos do Reino é leitura interessante no conjunto da historiografia sobre escravidão, que nele ganha um amplo painel da circulação de cativos entre a metrópole e a colônia. A descoberta desses circuitos alternativos do tráfico transatlântico descortina novas relações no mundo da escravidão luso-brasileira.

Daniela Buono Calainho calainho@globo.com

Universidade Estadual do Rio de Janeiro 